\title{
PROGRESSIVE MUSCULAR DYSTROPHY INVOLVING THE EXTRA-OCULAR MUSCLES* WITH NOTES CONCERNING OPERATIVE TREATMENT OF THE ASSOCIATED DIVERGENT SQUINT
}

\author{
BY \\ AHTI TARKKANEN AND VEIKKO TOMMILA \\ Helsinki University Eye Hospital, Helsinki, Finland
}

THE earliest sign in progressive muscular dystrophy of involvement of the extraocular muscles is usually a bilateral ptosis which is followed by slowly progressing immobility of the eyes. The central nervous system as well as the skeletal muscles may be affected. Furthermore, heart disorders have been reported. At present, the disorder is attributed to progressive dystrophy of the extra-ocular muscles and not to degeneration of the nuclei of the third, fourth, and sixth nerves as was thought before. The reader is referred to the papers on the subject by Kiloh and Nevin (1951) and Papst, Esslen, and Mertens (1958), and more recently, Lind and Prame (1963).

The present case showed dystrophic changes primarily in the extra-ocular muscles which led to marked restrictions of the ocular movements as well as to divergent squint. The condition was improved by squint surgery. The presenting sign was continuous lacrimation, and practically no ptosis could be observed.

\section{Case Report}

A 26-year-old miner complained of lacrimation and reading difficulties of one and a half years' duration. He had also noted that his eyes had started to deviate outwards. There was no family history of squint or other eye diseases; furthermore, the past history did not reveal any trauma similar to the cases reported by Senita and Fisher (1958). He was studied at the Medical Department of the University of Helsinki for chest pains and referred for eye examination to the Helsinki University Eye Hospital.

Medical Examination.-The findings were compatible with stenosis and insufficiency of the mitral valve as well as with the Wolff-Parkinson-White syndrome. A mitral commissurotomy was considered.

Neurological Examination.-Except for the squint, the findings were within normal limits. No evidence of myotonic dystrophy or of myasthenia gravis was obtained.

Electromyography.--Recordings were obtained from the left medial and inferior rectus muscles as well as from the orbicularis oculi, the orbicularis oris, and the brachioradial muscle.

The orbicularis oris and the brachioradial muscles showed normal firing, but the findings from the extra-ocular muscles were compatible with peripheral myopathy. No evidence of motoneural injury was obtained.

Ocular Findings in March, 1962.-Visual acuity of both eyes was 1.6. The media, the tensions, the fundi, and the visual fields were normal. A left divergent squint of $15^{\circ}$ was present. The amplitude of fusion was minimal and no stereopsis was found. The ductions and the vergences were markedly restricted in all directions of gaze. It is noteworthy that practically no ptosis could be observed.

When the examination was repeated ten months later, the angle of divergent squint was found to be increased. It now measured $23^{\circ}$. The ocular movements were now more restricted. Adduction measured $0^{\circ}$ and abduction $23^{\circ}$, elevation $5^{\circ}$, and depression $10-15^{\circ}$ (Fig. 1, opposite).

\footnotetext{
* Received for publication April 30, 1964.
} 

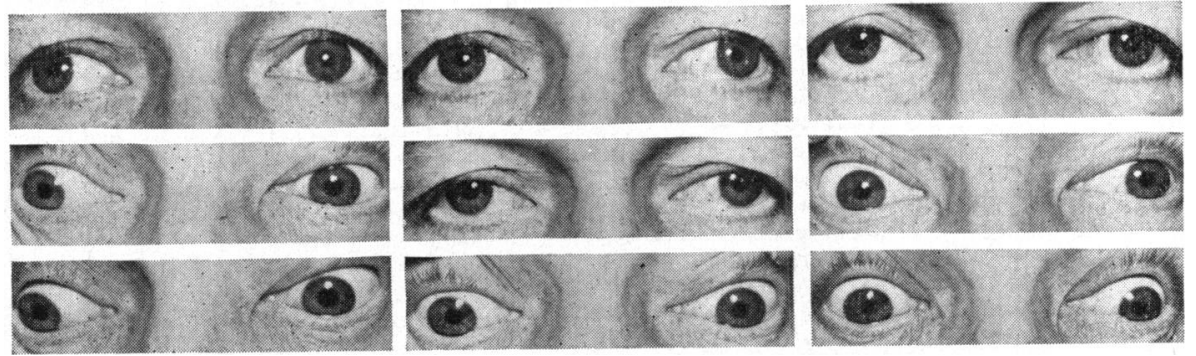

FIG. 1.-Pre-operative appearance. Marked limitations of the ocular movements in all directions of gaze are noted.

Operation.-The left medial rectus was resected $5 \mathrm{~mm}$. At operation the muscle appeared pale and was largely adherent to the surrounding tissues.

The angle of squint was reduced to $10^{\circ}$ and the patient reported the cessation of lacrimation in the left eye. Approximately six months later the right medial rectus was resected $5 \mathrm{~mm}$. at the patient's own request. A further decrease of the angle of squint resulted, now measuring $-4^{\circ}$ (Fig. 2). The patient reported the cessation of lacrimation also from the right eye and was satisfied with the improvement of his appearance.

Biopsy of the Pectoralis Muscle.-To exclude dystrophy of the skeletal muscles biopsy of the pectoralis major muscle was performed.

\section{Pathology.}

Ocular muscles.-On macroscopical examination two pieces of muscle, $3 \mathrm{~mm}$. and $4 \mathrm{~mm}$. long were noted.

The microscopical examination showed markedly atrophic muscle fibres with disappearance of cross striations in places. There was a marked

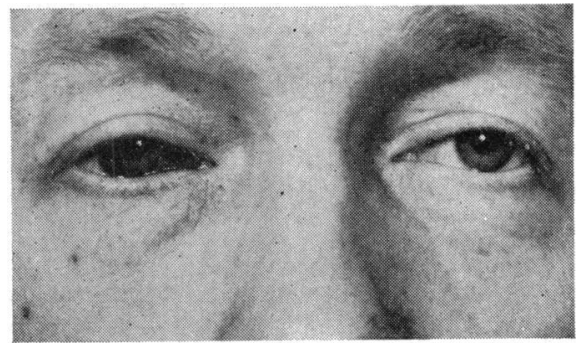

FIG. 2.-The appearance of the eyes following $5 \mathrm{~mm}$. resection of the medial rectus muscles.

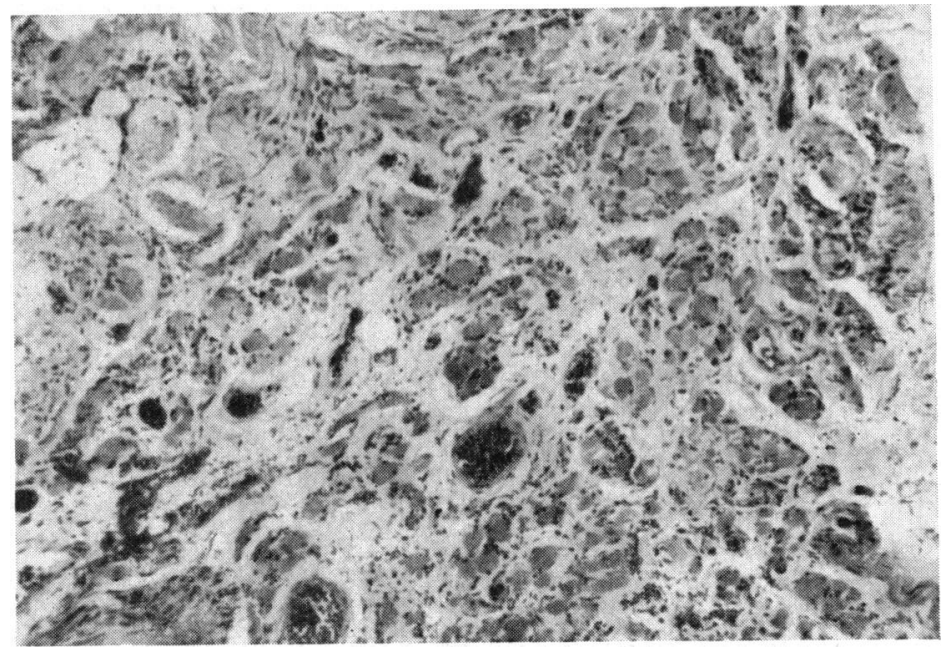

FIG. 3.-The medial rectus muscle. Atrophy of the muscle fibres as well as marked proliferation of the sarcolemmal nuclei is noted. Increase of the interstitial connective tissue and accumulation of fat between the muscle fibres have occurred. $\times 80$. 
proliferation of the sarcolemmal nuclei and an increase of the interstitial connective tissue, as well as accumulation of fat between the muscle fibres (Fig. 3).

Pectoralis muscle.-On macroscopical examination a piece of muscle $12 \mathrm{~mm} . \times 8 \mathrm{~mm}$. was noted.

The microscopical examination revealed essentially normal muscle with well-developed muscle fibres showing normal cross striations. There was no proliferation of sarcolemmal nuclei nor any increase of the interstitial fibrous tissue (Fig. 4).

Repeated Neurological Examination.-This was performed 22 months after the initial examination. Except for the ocular disorder the findings were within normal limits.

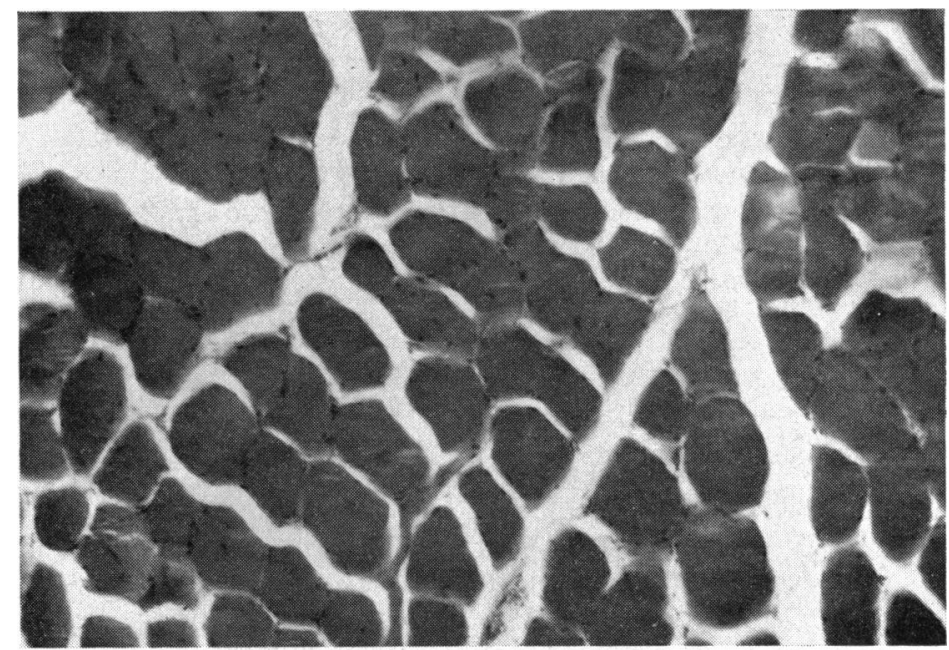

FIG. 4.-The pectoralis major muscle showing normal microscopic appearance. $\times 160$.

\section{Discussion}

A few features in the present case were of special interest.

The history, as well as the 24 months' period of observation, warranted the conclusion of the short duration and rapid progress of the disorder. In most of the reported cases the dystrophy has developed slowly (Kiloh and Nevin, 1951; McAuley, 1956; Lind and Prame, 1963; Sevel, 1964). According to Kiloh and Nevin (1951) the rapidly progressing cases should be subjected to some scepticism.

Histopathological examination revealed a marked muscular dystrophy of the extraocular muscles whereas the pectoralis major muscle appeared normal. Furthermore, electromyography showed the disorder to be present only in the extra-ocular muscles, while the skeletal muscles showed a normal firing pattern. Other studies (Kiloh and Nevin, 1951; McAuley, 1956; Kearns and Sayre, 1958; Papst and others, 1958; Lind and Prame, 1963), however, have usually disclosed dystrophic changes in skeletal muscles as well. Whether similar changes will appear in the present case cannot be determined as yet.

The presenting sign in external ophthalmoplegia is usually a bilateral ptosis (Kiloh and Nevin, 1951), although reports of its late appearance (Papst and others, 1958) as well as its complete absence (Heller, 1928) are available. In the present case, however, continuous lacrimation was the initial disturbing sign, and review of the literature revealed no previous observations of this phenomenon. 
The dystrophy of the extra-ocular muscles led to a marked divergent squint which was improved by squint surgery. The eyes were brought to an alignment and a subsequent cessation of the lacrimation resulted. The lacrimation could probably be explained by a slight ectropion of the lacrimal puncta when the eyes were in divergent position.

\section{Summary}

A case of progressive dystrophy involving the extra-ocular muscles is described. The patient was a 26-year-old male who complained of lacrimation and reading difficulties of one and a half years' duration. A congenital heart defect was found in the medical examination whereas the repeated neurological examinations were negative except for the ocular disorder. Electromyography showed a normal firing pattern in the skeletal muscles while the extra-ocular muscles showed changes compatible with peripheral myopathy. Biopsy of the ocular muscles was done as well as of the pectoralis major muscles and histopathological findings have been presented. The disorder led to a divergent squint which was successfully improved by squint surgery.

\section{REFERENCES}

HeLler, W. (1928). Z. Augenheilk., 64, 136.

Kearns, T. P., and Sayre, G. P. (1958). A.M.A. Arch. Ophthal., 60, 280.

KiLOH, L. G., and Nevin, S. (1951). Brain, 74, 115.

Lind, I., and Prame, G. (1963). Acta ophthal. (Kbh.), 41, 497.

MCAuley, F. D. (1956). Brit. J. Ophthal., 40, 686.

Papst, W., Esslen, E., and Mertens, H. G. (1958). Klin. Mbl. Augenheilk., 132, 691.

SenitA, G. R., and Fisher, E. R. (1958). A.M.A. Arch. Ophthal., 60, 422.

SeVEL, D. (1964). Brit. J. Ophthal., 48, 39. 